\title{
Prediction of an Optimum Total Resistance Coefficient on Catamaran using Design of Experiment (DOE) Incorporated with CFD Approach
}

\author{
Ahmad Fitriadhy ${ }^{\mathrm{a}, *}$, Sun Yin Lim ${ }^{\mathrm{b}}$, Adi Maimun ${ }^{\mathrm{c}}$ \\ ${ }^{a}$ School of Ocean Engineering, University Malaysia Terengganu. Email: naoe.afit@gmail.com

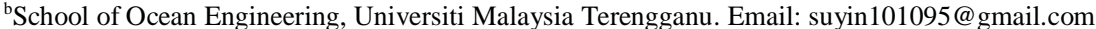 \\ cDepartment of Aeronautics, Automotive and Ocean Engineering. University Technology Malaysia. Email: adi@utm.my
}

\begin{abstract}
In the presence of complex hydrodynamic interferences between two demihulls on a catamaran ship has been prone to have a reliable prediction to her optimum total resistance. To achieve this, the author presents a Computational Fluid Dynamic (CFD) modelling incorporated with Design of Experiment (DOE) approach. Several parameters such as effect of Froude number $\left(F_{r}\right)$ with respect to various lateral separation ratios $(\mathrm{S} / \mathrm{L})$ of the catamaran have been taken into account. Here, the optimum total resistance coefficient $\left(\mathrm{C}_{\mathrm{T}}\right)$ has been mainly set within the range of $\mathrm{S} / \mathrm{L}$ ratio $0.2 \leq \mathrm{S} / \mathrm{L} \leq 0.4$ associated with Froude number $0.56 \leq F_{r} \leq 0.66$. The primary objective function of this optimization model has led towards minimizing a drag force and increased a lift force with respect to the above $\mathrm{S} / \mathrm{L}$ ratios. In general, the simulation results had seemed quantitative similarity values for the optimum $F_{r}$ of $0.6589,0.6599$ and 0.6596 with S/L ratios of $0.2,0.3$ and 0.4 , respectively. In the case of $F_{r}=0.56$, the optimum S/L ratios of 0.2993 and 0.3988 have resulted in insignificant reduction of $\mathrm{C}_{\mathrm{T}}$ by $0.62 \%$ and $0.32 \%$ as compared to $\mathrm{S} / \mathrm{L}$ of 0.3 and 0.4 , respectively. Similarly, the optimum $\mathrm{S} / \mathrm{L}$ ratios of 0.2750 and 0.3750 with $F_{r}=0.66$ have led to reduce by $0.14 \%$ and $0.46 \%$ as compared to $\mathrm{S} / \mathrm{L}$ of 0.3 and 0.4 , respectively. This CFD simulation results are very useful as preliminary data for the optimised ship resistance, which is mainly required to predict a ship powering in the early design stage.
\end{abstract}

Keywords: Catamaran; Froude number; lateral separation ratio; optimization; total resistance coefficient

\section{Introduction}

A catamaran is a multi-hulled vessel featuring two parallel hulls of equal size. Catamaran's native nature accords some advantages such as speed, carrying capacity [1] better stability and hydrodynamic performance [2], [3]. Yet, catamaran ships encounter less resistance due to presence of lower draft as compared to demi hull ship [4].

Correspondingly, substantial amount of research has been carried out in late year to review the resistance characteristics of catamaran. This is necessary because resistance behavior of the catamaran is clearly different when compared to the demi hull ships [5], [6]. The effect of lateral separation ratio (S/L) between two demi hulls have revealed that the change of the lateral distance between two demi hulls on the catamaran contributed a significant effect to the resistance components [7]-[9]. This is supported by investigation of A. Fitriadhy that different $\mathrm{S} / \mathrm{L}$ ratio having the significant different values of total resistance coefficient. His research showed that

*Corresponding author. Tel.: +609-668-3856

Universiti Malaysia Terengganu

Kuala Terengganu, Malaysia, 21030 as Fr number increasing from 0.47 to 0.66 , there are a significant loss of the total resistance coefficient. The unfavorable Froude number predominantly occurred at $F_{r}$ $=0.47$ regardless of $\mathrm{S} / \mathrm{L}$, which directly corresponds to arise in the peak total resistance coefficient [10], [11]. Hence, this region $0.47 \leq F_{r} \leq 0.66$ had become a great interest of area to be study. It is evident that a significant reduction in resistance could be achieved by finding the optimum position of stagger [12]. Experimental work in towing tank is relatively time-consuming, expensive and impractical for various resistance test configurations. Furthermore, optimization scheme unable to be achieve in towing work. But it is possible to be carried out with Computational Fluid Dynamic (CFD) as published by Anantha [13]. It is clear that a reliable CFD approach has become necessary at gaining more accurate predictions of the total resistances in various lateral separation ratios. However, an increase of speed results in proportionally increase in her resistance. Therefore, a prediction of optimum resistance for catamaran has become primary requirement towards obtaining a better efficiency associated with lower operating cost.

This paper presents an optimization modelling simulation to obtain an optimum Froude number with 
respect to various $\mathrm{S} / \mathrm{L}$ ratio and also to obtain the optimum $\mathrm{S} / \mathrm{L}$ ratio on a rounded catamaran using Design of Experiment (DOE) approach incorporated with Computational Fluid Dynamic. This method has been possibly applied to deal with assessment of the optimum $\mathrm{S} / \mathrm{L}$ ratio, which results in lesser total resistance coefficient for prescribed speed. Several parameters such as effects of the lateral separations ratio $(\mathrm{S} / \mathrm{L})$ between 0.2 to $0.3,0.3$ to 0.4 and its corresponding total resistance coefficient of a rounded hull catamaran form in calm water over a range of Froude number have been taken into account in the simulation. Here, a commercial CFD software of ANSYS FLUENT 18.0 is used with the coupling of parameter.

\section{Governing Equations}

ANSYS FLUENT models the numerical solution of the Reynolds Averaged Navier-Strokes Equations (RANSE) along with the Volume of Fluid (VOF) method for simulating the free surface flow. The k-epsilon $(\mathrm{k}-\varepsilon)$ turbulence model has been used in viscous flow code for meshing the computational domain. Besides, inflation layer was treated as the interface between air and water, to accurately capture the boundary layer region for any wall-bounded turbulent flows.

\subsection{Total resistance prediction of a ship}

In FLUENT, the total force component along the specified force vector $\vec{a}$ on a wall zone is computed by summing the dot product of the pressure and viscous forces on each face with the specified force vector. The terms in this summation represent the pressure and viscous force components in the direction of the vector $\vec{a}$

$$
F_{a}=\vec{a} \cdot \vec{F}_{P}+\vec{a} \cdot \vec{F}_{V}
$$

where, $F_{a}$ is the total force component, $\vec{a}$ is the specified force vector, $\vec{F}_{P}$ is the pressure force vector and $\vec{F}_{V}$ is the viscous force vector [14]. William Froude is known as the pioneer on the prediction of ship resistance using a model which is far smaller than the real ship [15]. The total resistance of a ship is expressed in Eq. (2) as the sum of the frictional resistance $\left(R_{F}\right)$ and the residual resistance or known as the pressure resistance $\left(R_{P}\right)$.

$$
R_{T}=R_{F}+R_{P}
$$

where the coefficient of the total resistance according to ITTC [16] is expressed as

$$
C_{T}=\frac{R_{T}}{0.5 \times \rho \times W S A \times V_{S}^{2}}
$$

where, $R_{T}$ is the dimensional total resistance, $\rho$ is the water density, WSA is the wetted surface area of the ship and $V_{S}$ is the forward ship speed.

\subsection{Volume fraction equation}

The tracking of the interface between the air and water phases is accomplished by the solution of a continuity equation for the volume fraction of two phases. For the $q^{\text {th }}$ phase, this equation has the following form

$$
\begin{aligned}
\frac{1}{\rho_{q}}=\left[\frac{\partial}{\partial t}\left(\alpha_{q} \rho_{q}\right)\right. & +\nabla \cdot\left(\alpha_{q} \rho_{q} \vec{v}_{q}\right) \\
& \left.=S_{\alpha_{q}}+\sum_{p=1}^{n}\left(\dot{m}_{p q}-\dot{m}_{q p}\right)\right]
\end{aligned}
$$

where $\dot{m}_{q p}$ is the mass transfer from phase $q$ to phase $p$ and $\dot{m}_{p q}$ is the mass transfer from phase $p$ to phase $q$ [17]. The volume fraction equation is solved through implicit time discretization. ANSYS FLUENT's standard finite-difference interpolation schemes, QUICK, Second Order Upwind and the Modified HRIC schemes, are used to obtain the face fluxes for all cells, including those near the interface.

\subsection{Turbulence model}

In this CFD simulation, we propose the Realizable $k-\varepsilon$ Model, which is available In FLUENT solver. The term "realizable" means that the model satisfies certain mathematical constraints on the Reynolds stresses, consistent with the physics of turbulent flows. The modeled transport equations for $k$ and $\varepsilon$ in the realizable $k-\varepsilon$ model are

$$
\begin{aligned}
& \frac{\partial}{\partial t}(\rho k)+\frac{\partial}{\partial x_{j}}\left(\rho k u_{j}\right) \\
& =\frac{\partial}{\partial x_{j}}\left[\left(\mu+\frac{\mu_{t}}{\sigma_{k}}\right) \frac{\partial k}{\partial x_{j}}\right]+G_{k}+G_{b}-\rho \varepsilon-Y_{M}+S_{k}
\end{aligned}
$$

In these equations, $G_{k}$ represents the generation of turbulence kinetic energy due to the mean velocity gradients, $G_{b}$ is the generation of turbulence kinetic energy due to buoyancy, $Y_{M}$ represented the contribution of the fluctuating dilatation in compressible turbulence to the overall dissipation rate [18].

Cell meshing size is one significant point that should observed. Thus, first cell height for inflation need to be estimated, depends on the local Reynolds number, which is computed based on the wall variable $\mathrm{y}^{+} . \mathrm{Y}^{+}$is a dimensionless parameter illustrating local Reynolds number in the near wall region. In this study, the authors choose $\mathrm{y}^{+}=8$ for low Fr number and $\mathrm{y}^{+}=50$ for high Fr number.

$$
y^{+}=\frac{p U_{\text {fric }} y_{w a l l}}{\mu}
$$

where $U_{\text {fric }}$ is the friction velocity, $U_{\text {fric }}=\sqrt{\frac{\tau_{\text {wall }}}{\rho}}$, $\tau_{\text {wall }}=\frac{C_{f} \rho V_{S}^{2}}{2}$ and $C_{f}=\frac{0.026}{R e^{1 / 7}}$

\subsection{Optimization}

Optimizing a design with multiple objective functions is needed in this paper. These situations can be described in general mathematical forms as follows. The design variables are denoted by: 


$$
\vec{X}=\left[x_{1}, x_{2}, x_{3}, \ldots, x_{n}\right] \in D^{n}
$$

where $n$ represents total number of design variables and $D^{n}=n$-dimensional design space, and defined by:

$$
x_{i, \min } \leq x_{i} \leq x_{i, \max }, i=1,2,3, \ldots . n
$$

Optimization of a ship hull from a resistance point of view forms a non-linear optimization problem [19]. There are two objectives here. The first one is to optimize an output variable $\left(C_{T}\right)$ which is influence by input variable (Fr number). The second one is to optimize an output variable $\left(C_{T}\right)$ which is influenced by input variable ( $\mathrm{S} / \mathrm{L}$ ratio).

\subsubsection{Design of experiment using central composite design}

Central Composite Designs, also known as BoxWilson Designs, are a five-level fractional factorial design that is suitable for calibrating the quadratic response model [20]. Face-centered CCDs is chosen in this study. The five-level coded values of each factor are represented by

$$
[-\alpha,-1,0,+1,+\alpha]
$$

where $[-1,+1]$ corresponds to the physical lower and upper limit of the explored factor space. It is obvious that $[-\alpha,+\alpha]$ establishes new "extreme" physical lower and upper limits for all factors. The value of $\alpha$ varies depending on design property and number of factors in the study [20].

Face-centered CCDs are a special case of Central Composite Designs in which $\alpha=1$. As a result, the facecentered CCDs become a three-level design that is located at the center of each face formed by any two factors. Figure 1 is a geometrical representation of a facecentered CCD of three factors [20].

\subsubsection{Response surface types using genetic aggregation}

The Genetic Aggregation response surface's selection of the best response surface is based on a genetic algorithm generating populations of different response surfaces solved in parallel. The fitness function of each response surface is used to determine which one yields the best approach. It takes into account both the accuracy

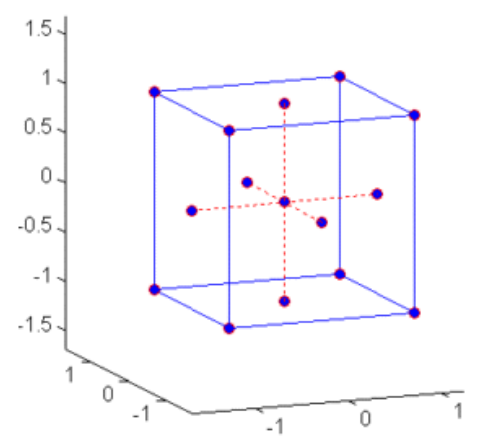

Figure 1. Central composite design for face-centered. of the response surface on the design points and the stability of the response surface (cross-validation) [21]. The Genetic Aggregation response surface can be written as an ensemble using a weighted average of different meta models:

$$
\hat{y}_{\text {ens }}(x)=\sum_{i=1}^{N_{M}} w_{i} \cdot \hat{y}_{i}(x)
$$

where $\hat{y}_{\text {ens }}$ is prediction of the ensemble, $\hat{y}_{i}$ is prediction of the $i$-th response surface, $N_{M}$ is number of meta models used, $N_{M} \geq 1$ and $w_{i}$ is weight factor of the $i$-th response surface. DesignXplorer minimizes the Root Mean Square Error (RMSE) of the Design Point on $\hat{y}_{\text {ens }}$ to estimate the best weight factor values.

$$
\operatorname{RMSE}\left(\hat{y}_{\text {ens }}\right)=\sqrt{\frac{1}{N} \sum_{j=1}^{N}\left(y\left(x_{j}\right)-\hat{y}_{\text {ens }}\left(x_{j}\right)\right)^{2}}
$$

where $x_{j}$ is $j^{\text {th }}$ Design Point, $y\left(x_{j}\right)$ is output parameter value at $x_{j}$ and $N$ number of Design Points.

\section{Simulation Condition}

The hull geometry has been imported into ANSYS Workbench, which was generated from CAD software. The principal dimension of the catamaran model in Fig. 2 is given completely in Table 1 .

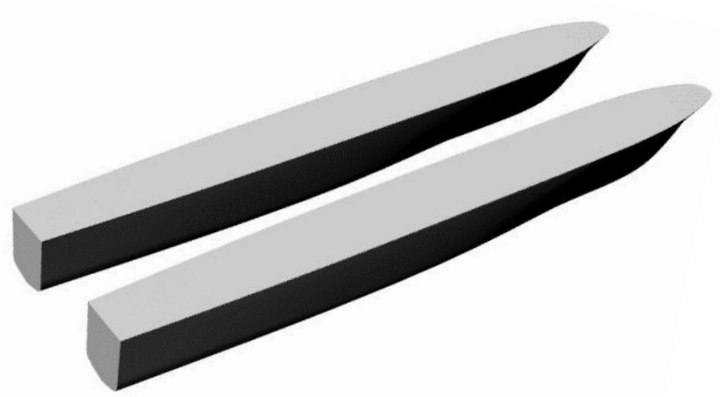

Figure 2. Rounded hull catamaran model

Table 1. Principle dimension of a rounded hull catamaran model

\begin{tabular}{lll}
\hline Description & Demi hull & Catamaran \\
\hline Length $(\mathrm{m})$ & 1.3720 & 1.3720 \\
Breadth $(\mathrm{m})$ & 0.12300 & - \\
Draught $(\mathrm{m})$ & 0.0780 & 0.0780 \\
Wetted Surface Area, & 0.2510 & 0.5020 \\
WSA $\left(\mathrm{m}^{2}\right)$ & & \\
Volume $\left(\mathrm{m}^{3}\right)$ & 0.0072 & 0.0144 \\
Displacement $(\mathrm{kg})$ & 7.2220 & 14.444 \\
Vertical Center of & 0.0490 & 0.0490 \\
Buoyancy $(\mathrm{m})$ & & \\
\hline
\end{tabular}




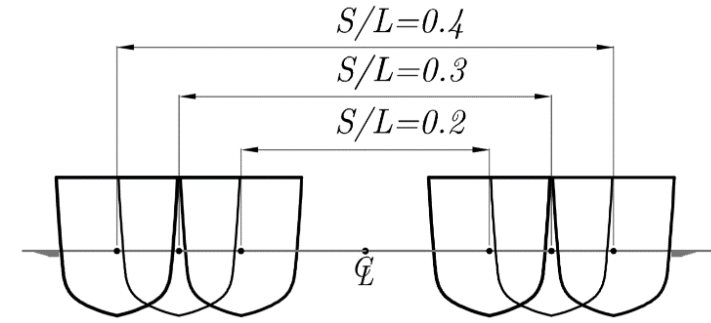

Figure 3. Simulation conditions on predicting total resistances on the catamaran due to effect of S/L.

Table 2. Matrix of simulation

\begin{tabular}{ccc}
\hline $\begin{array}{c}\text { Matrix of CFD } \\
\text { Simulation }\end{array}$ & \multicolumn{2}{c}{ Froude Number } \\
\hline \multirow{2}{*}{ S/L } & 0.2 & \\
& 0.3 & $0.19,0.28,0.37,0.47,0.56$ and 0.66 \\
& 0.4 & \\
\hline
\end{tabular}

\subsection{Simulation parameter}

Several parameters such as effects of the lateral separations ratio (S/L) against various Froude number $(\mathrm{Fr})$ from 0.19 to 0.66 were taken into account as shown in Fig. 3. The details of simulation parameters are summarized in Table 2. Computational domain and meshing generation.

Referring to Table 3, pressure inlet and outlet are set to open channel flow with free surface and bottom level defined. Some assumptions were made for mathematical model settings such as catamaran speed is constant and the water surfaces are calm without waves. Interpolation scheme used for pressure is PRESTO due to there are strong body forces present. Volume fraction used is modified HRIC to overcome difficulties in interface tracking because of their overly diffusive nature.

The domain (Fig. 4) must be sufficiently large in the horizontal direction to prevent the influence of flow by boundaries. It provides computational efficiency where less nodes and elements are required to achieve high solution accuracy [22]. Meshing cell used in this case is purely tetrahedral meshes with 10 prism layers (Fig. 5) as it is relatively complex geometries [23]. Besides, the free-surface flow requires a fine grid. Inflation is required here. The authors apply the symmetrical computational domain model considering on less computational time.

Table 3. Boundary setting conditions

\begin{tabular}{lcll}
\hline Description & $\begin{array}{c}\text { Distance with } \\
\text { respect to } \\
\text { origin point }\end{array}$ & \multicolumn{1}{c}{ Type } & Description \\
\hline $\mathrm{X}_{\max }$ (Inlet) & $1.0 \mathrm{~L}_{\mathrm{pp}}$ & Pressure inlet & Open channel \\
$\mathrm{X}_{\min }$ (Outlet) & $3.0 \mathrm{~L}_{\mathrm{pp}}$ & Pressure outlet & Open channel \\
$\mathrm{Y}_{\min }($ Side $)$ & $1.5 \mathrm{~L}_{\mathrm{pp}}$ & Stationary wall & Zero viscous stress \\
$\mathrm{Y}_{\max }($ Side) & $1.5 \mathrm{~L}_{\mathrm{pp}}$ & Stationary wall & Zero viscous stress \\
$\mathrm{Z}_{\min }$ (Bottom) & $1.5 \mathrm{~L}_{\mathrm{pp}}$ & Moving wall & Vessel speed \\
$\mathrm{Z}_{\max }$ (Top) & $0.5 \mathrm{~L}_{\mathrm{pp}}$ & Stationary wall & Zero viscous stress \\
\hline
\end{tabular}

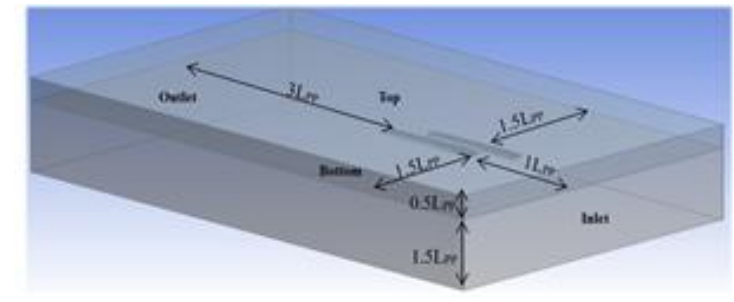

Figure 4. Domain dimension and boundary conditions

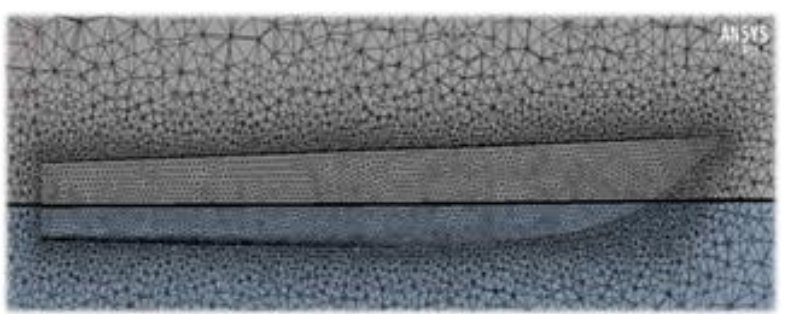

Figure 5. Tetrahedral meshes and 10 prism layers as inflation

Table 4. Mesh independence study

\begin{tabular}{lll}
\hline $\begin{array}{l}\text { Number of } \\
\text { Elements }\end{array}$ & $\begin{array}{l}\text { Resistance, } \\
R_{T}(N)\end{array}$ & $\begin{array}{l}\text { Percentage of } \\
\text { Difference }(\%)\end{array}$ \\
\hline 145,853 & 15.208 & - \\
288,802 & 14.023 & 8.45 \\
572,421 & 13.102 & 7.21 \\
$1,152,100$ & 12.421 & 5.48 \\
$2,288,364$ & 11.836 & 13.9 \\
$4,583,156$ & 11.815 & 0.18 \\
\hline
\end{tabular}

Mesh independence study is performed to ensure that the total resistance conformed to convergence and meshindependence criteria. Table 4 illustrates a summary of ship resistance calculations, using different number of elements. In this study, 2,288,364 (or approximately 2.3 million) elements in the simulation, satisfies the meshindependence criterion.

\section{Results and Discussions}

As seen in the following figures (Figs. 7-9), the CFD simulations on predicting resistance on rounded hull catamaran had been successfully carried out at various Froude number with $\mathrm{S} / \mathrm{L}$ ratios. The simulation results are appropriately discussed in sub-sections 4.1, 4.2 and 4.3 , respectively.

\subsection{Effect of Froude number $(\mathrm{Fr})$ on catamaran}

Figure 6(a) shows that the increase of $F_{r}$ was proportional to the total resistance $\left(\mathrm{R}_{\mathrm{T}}\right)$ on the catamaran, where a maximum increment of about $135 \%$ occurred as $F_{r}$ increased from 0.19 to 0.28 . The detailed results of the resistance prediction for the catamaran is summarized in Table 5. The results correspond to the fact that increase of wave crest and trough near the body of hull [10]. At $F_{r} 0.47$, the catamaran reached the highest total resistance coefficient. The result was found to be similarly to the work previously reported by Papanikolaou and Dafnias [24], where $F_{r}$ around 0.45 was identified as an unfavourable Froude number for the catamaran resistance. 


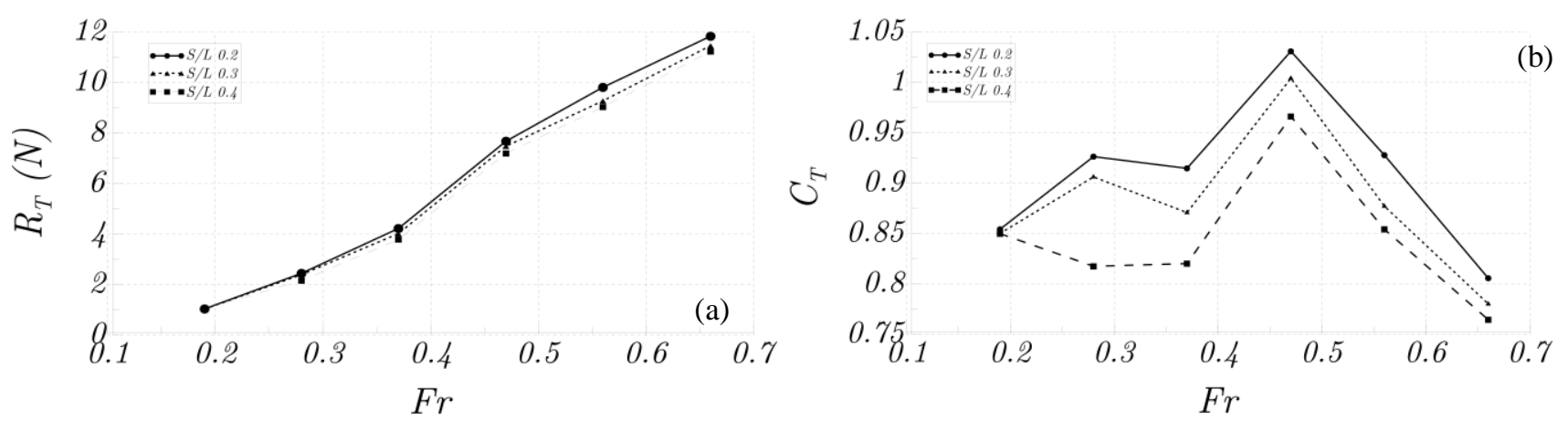

Figure 6. Total resistance for catamaran with $\mathrm{S} / \mathrm{L}=0.2$ to 0.4 at various Froude numbers
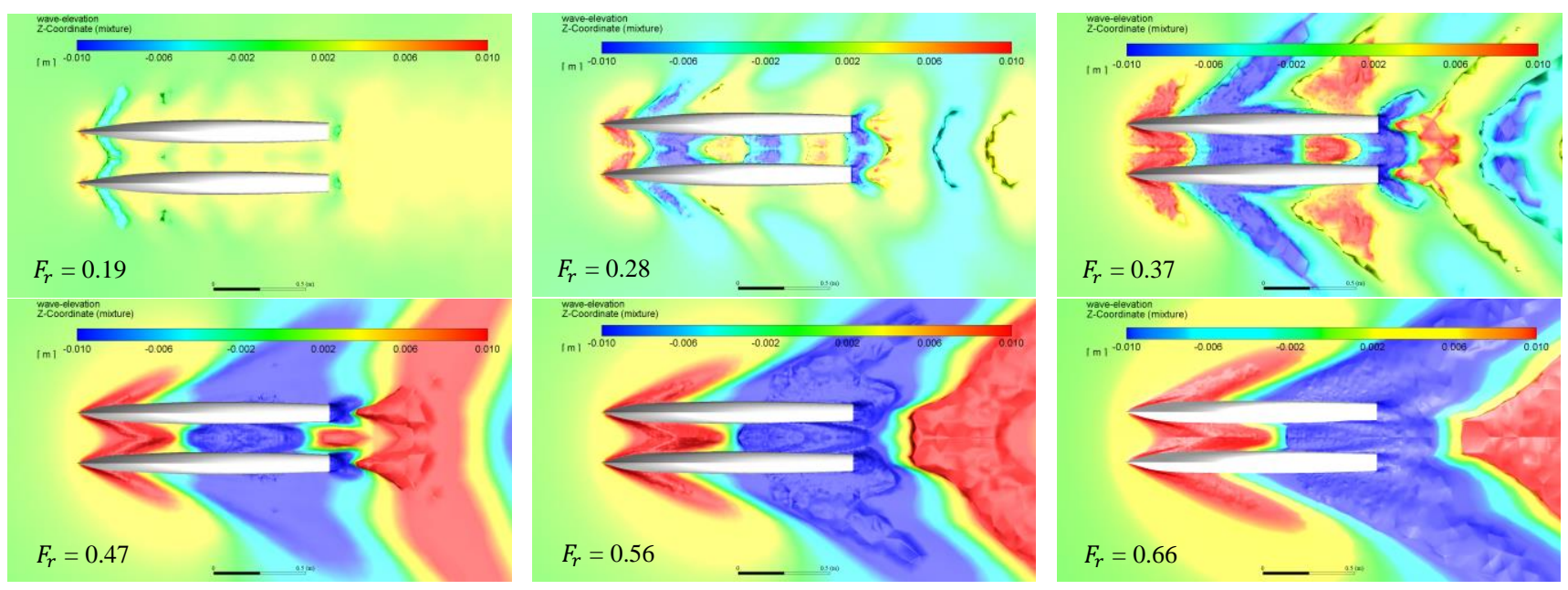

Figure 7. Wave pattern characteristics of catamaran $(S / L=0.2)$
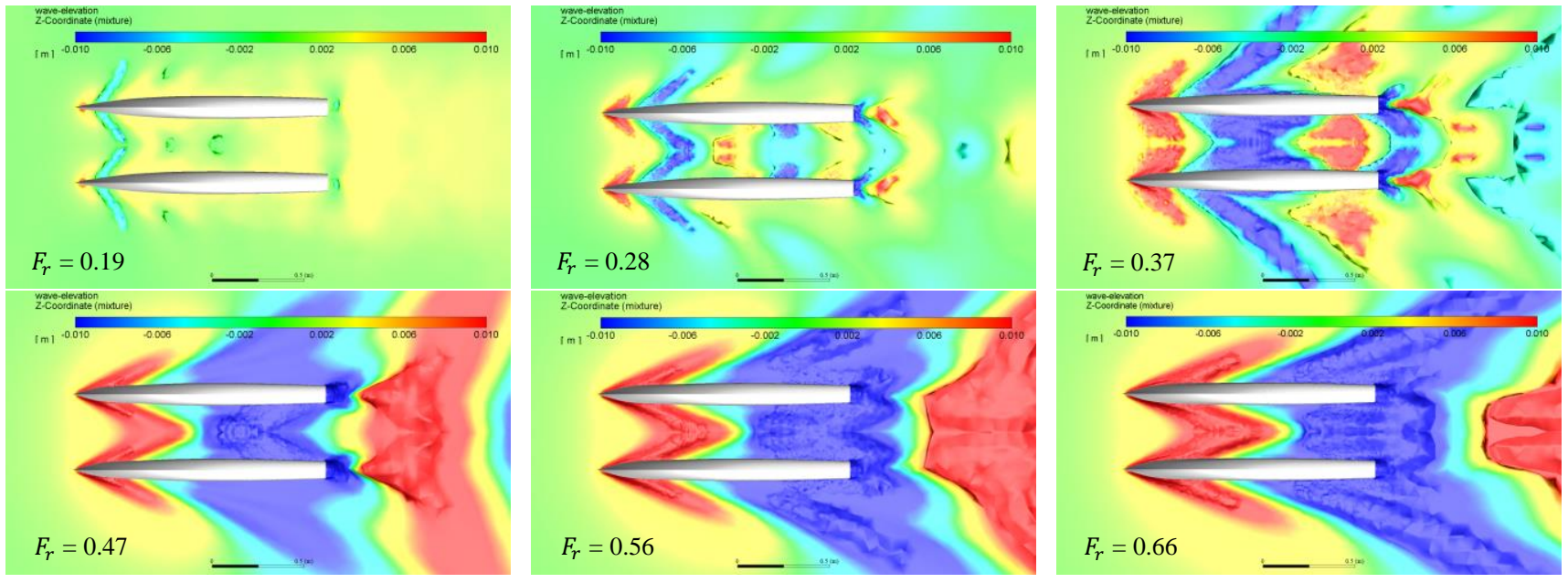

Figure 8. Wave pattern characteristics of catamaran $(S / L=0.3)$ 

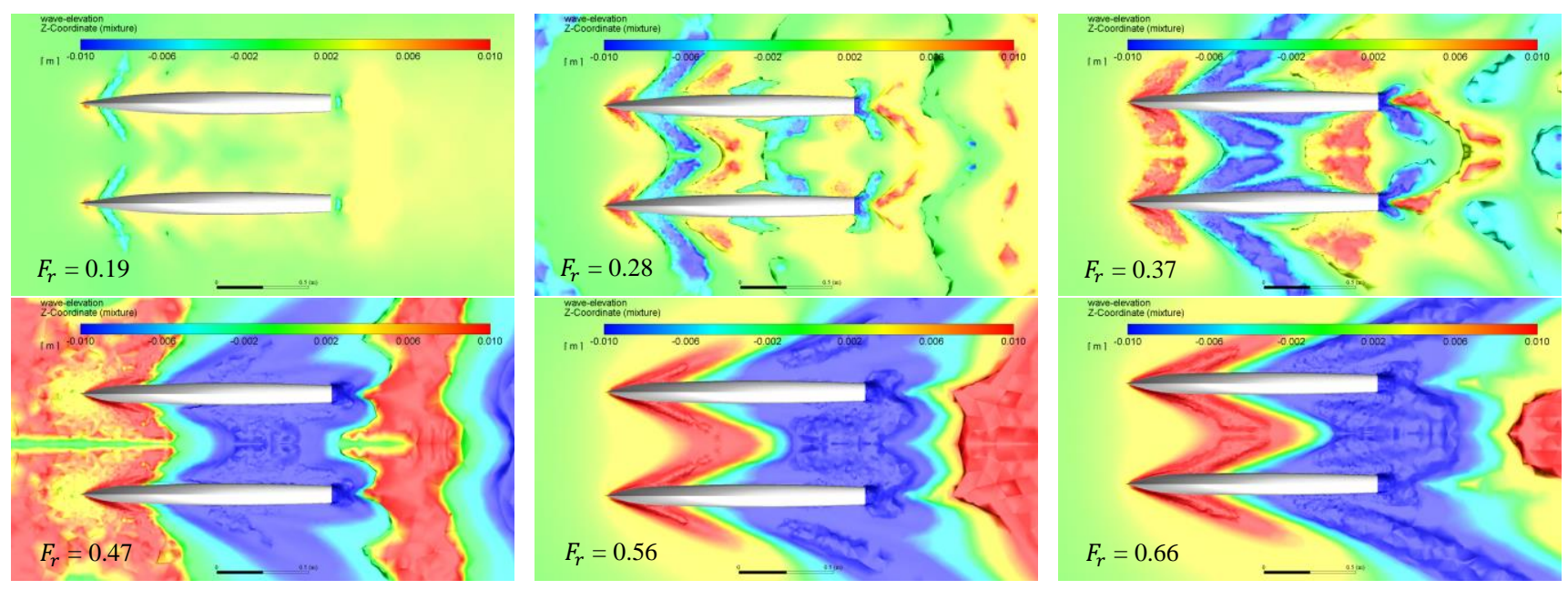

Figure 9. Wave pattern characteristics of catamaran $(\mathrm{S} / \mathrm{L}=0.4)$

Table 5. Total resistance coefficient at S/L 0.2 to 0.4

\begin{tabular}{cccccc}
\hline S/L & Froude No. & $R_{T}(N)$ & Discrepancy of $R_{T}$ & $C_{T}$ & Discrepancy of $C_{T}$ \\
\hline \multirow{6}{*}{0.2} & Fr & CFD & $\%$ & CFD & $\%$ \\
\cline { 2 - 6 } & 0.19 & 1.04006 & - & 0.00854 & - \\
& 0.28 & 2.44924 & 135.49 & 0.00926 & 8.43 \\
& 0.37 & 4.22312 & 72.43 & 0.00915 & -1.26 \\
& 0.47 & 7.67966 & 81.85 & 0.01031 & 12.68 \\
& 0.56 & 9.81270 & 27.78 & 0.00928 & -10.00 \\
0.3 & 0.66 & 11.83626 & 20.62 & 0.00806 & -13.16 \\
\hline \multirow{6}{*}{0.3} & 0.19 & 1.03500 & - & 0.00850 & - \\
& 0.28 & 2.39603 & 131.50 & 0.00906 & 6.60 \\
& 0.37 & 4.02042 & 67.80 & 0.00871 & -3.91 \\
& 0.47 & 7.47984 & 86.05 & 0.01004 & 15.30 \\
0.4 & 0.56 & 9.27706 & 24.03 & 0.00877 & -12.63 \\
& 0.66 & 11.46229 & 23.55 & 0.00780 & -11.05 \\
\hline \multirow{6}{*}{0.19} & 1.03472 & - & 0.00850 & - \\
& 0.19 & 108.92 & 0.00818 & -3.80 \\
& 0.28 & 2.16170 & 75.18 & 0.00820 & 0.32 \\
& 0.37 & 3.78697 & 90.07 & 0.00966 & 17.79 \\
& 0.47 & 7.19772 & 25.53 & 0.00854 & -11.58 \\
& 0.56 & 9.03499 & 24.32 & 0.00765 & -10.50 \\
\hline
\end{tabular}

\subsection{Lateral separation ratio $(S / L)$ on catamaran}

Regardless of lateral separation ratios, the results showed the subsequent increase of Froude number from 0.47 to 0.66 was proportional to the total resistance coefficient as displayed in Fig. 6(b). As the lateral separation ratios increases, the corresponding total resistance and total resistance coefficient decreases. The result was found to be similarly to the work previously reported by A. Fitriadhy [6], [10], Molland [8], Subramanian and Sahoo [9], where increasing of S/L ratio will decrease the total resistance [25], [26]. This occurred mainly due to the less contribution of wave interference and viscous effects between the two demihulls [10].

\subsection{Optimization of $\mathrm{Fr}$ number in various $S / L$ ratio}

As we can see that from subsection 4.2, total resistance coefficient reaches the highest peak for $F_{r}=$ 0.47 regardless of $\mathrm{S} / \mathrm{L}$ ratio. After $F_{r}=0.47$, total resistance coefficient decrease significantly in the range of $F_{r} 0.47$ to 0.66 (Table 5). The lower the speed of the vessel, it is expected that fuel consumption and ship emissions are also reduced [25]. Hence, we are interested to obtain an optimized $F_{r}$ for each $\mathrm{S} / \mathrm{L}$ ratio from the range 0.2 to 0.4. We will perform Design of Experiment (DOE) from $F_{r} 0.47$ to $F_{r} 0.66$. The existing $F_{r}$ will be $0.47,0.56$ and 0.66 . The number of design points need to be carefully determined based on the number of input factors and their ranges as well as the response model accuracy [27]. Hence, 2 design points will be added in between the existing $F_{r}$ as shown in Table 6 .

Response surface is performed, thus minimum and maximum calculated values appeared among the 8 design points. Optimization is then carried out with the objective to obtain an optimized $F_{r}$ that have total resistance and also total resistance coefficient that lesser than the value of $F_{r}=0.66$. As the trend for total resistance coefficient declined from $F_{r}=0.47$ to $F_{r}=0.66$. Somehow there is a point that between those ranges, there is a lower $C_{T}$ compared to $F_{r}=0.66$. Table 7 below shows the comparison of total resistance coefficient for the optimized $F_{r}$ with respect to $F_{r}=0.66$ for various S/L. The computed wave patterns characteristics for the catamaran with optimized $F_{r}$ compared to existing $F_{r}=$ 0.66 are presented below in Fig. 10. 
Table 6. Additional design points for $F_{r}=0.47$ to 0.70 for various S/L

\begin{tabular}{ccccc}
\hline S/L & $\boldsymbol{F}_{\boldsymbol{r}}$ & Total Resistance, $\boldsymbol{R}_{\boldsymbol{T}}$ & Total Resistance Coefficient, $\boldsymbol{C}_{\boldsymbol{T}}$ & Discrepancy of $\boldsymbol{C}_{\boldsymbol{T}}(\boldsymbol{\%})$ \\
\hline \multirow{6}{*}{0.47} & 7.67965580 & 0.010309358 & - \\
& 0.50 & 8.35270580 & 0.009907698 & -3.90 \\
& 0.53 & 9.12483220 & 0.009632937 & -2.77 \\
& 0.56 & 9.81270200 & 0.009278935 & -3.67 \\
& 0.60 & 10.5472960 & 0.008688088 & -6.37 \\
& 0.63 & 11.1728106 & 0.008347702 & -3.92 \\
& 0.66 & 11.8362646 & 0.008057724 & -3.47 \\
& 0.70 & 12.9357172 & 0.007828527 & -2.84 \\
\hline \multirow{6}{*}{0.47} & 7.47984400 & 0.010041126 & - \\
& 0.50 & 8.16363880 & 0.009683433 & -3.56 \\
& 0.53 & 8.66383060 & 0.009146266 & -5.55 \\
& 0.56 & 9.27707560 & 0.008772445 & -4.09 \\
& 0.60 & 10.1522756 & 0.008362700 & -4.67 \\
& 0.63 & 10.7705714 & 0.008047171 & -3.77 \\
& 0.66 & 11.4622898 & 0.007803135 & -3.03 \\
& 0.70 & 12.3832724 & 0.007494194 & - \\
\hline \multirow{6}{*}{0.47} & 7.19771800 & 0.009662393 & -3.46 \\
& 0.50 & 7.86430400 & 0.009328372 & -3.61 \\
& 0.53 & 8.51746600 & 0.008991751 & -4.98 \\
0.4 & 0.56 & 9.03499320 & 0.008543530 & -5.17 \\
& 0.60 & 9.83548880 & 0.008101754 & -3.18 \\
& 0.63 & 10.4989298 & 0.007844216 & -2.52 \\
& 0.66 & 11.2320536 & 0.007646398 & -4.48 \\
\hline
\end{tabular}

Table 7. Optimized $F_{r}$ with its corresponding total resistance coefficient for various S/L

\begin{tabular}{ccccc}
\hline S/L & $F_{r}$ & Total Resistance, $R_{T}$ & Total Resistance Coefficient, $C_{T}$ & Discrepancy of $C_{T}(\%)$ \\
\hline \multirow{2}{*}{0.2} & 0.6589 & 11.7956312 & 0.008055673 & - \\
& 0.6600 & 11.8362646 & 0.008057724 & 0.0250 \\
\hline \multirow{2}{*}{0.3} & 0.6599 & 11.4603770 & 0.007803015 & - \\
& 0.6600 & 11.4622898 & 0.007803135 & 0.0015 \\
\hline \multirow{2}{*}{0.4} & 0.6596 & 11.2088390 & 0.007639852 & - \\
& 0.6600 & 11.2320536 & 0.007646398 & 0.0860 \\
\hline
\end{tabular}
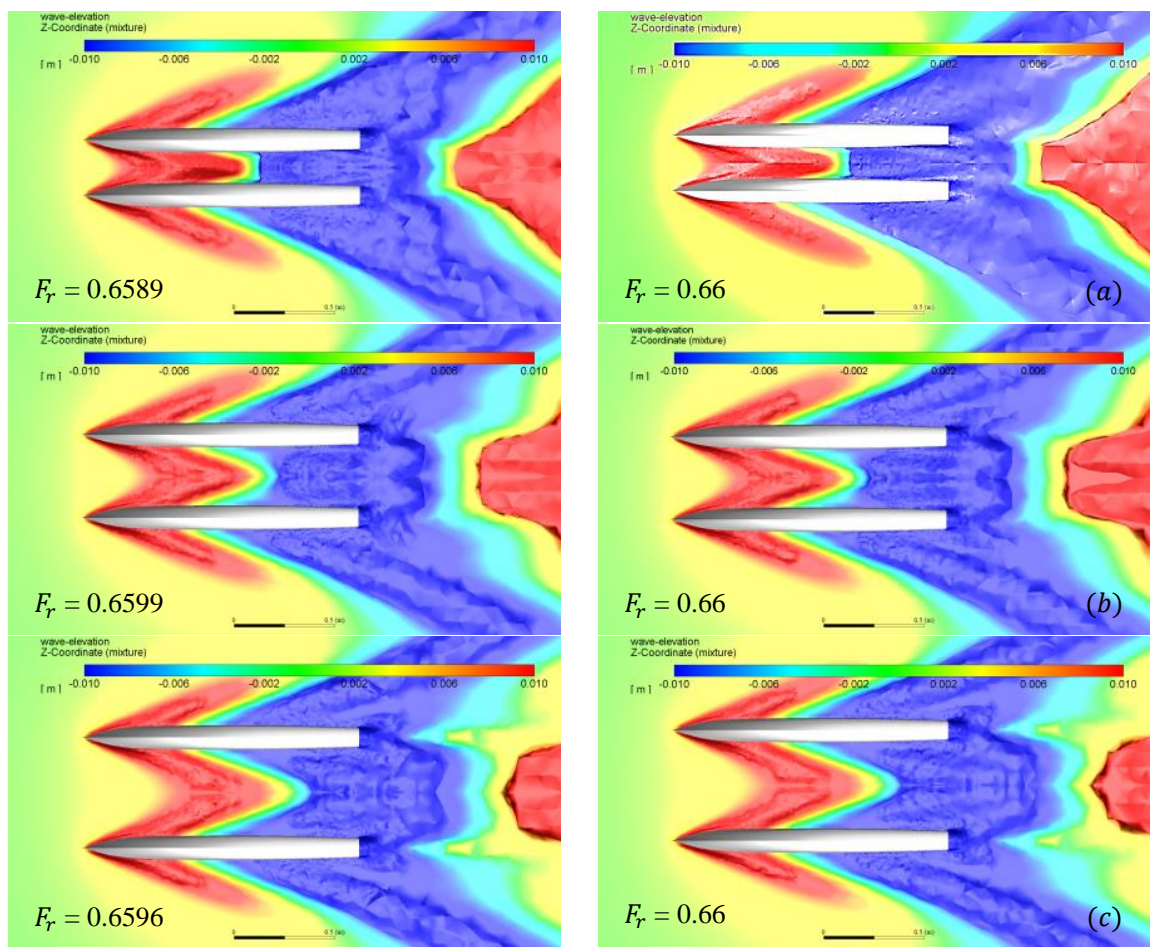

Figure 10. Wave patterns of optimized $F r$ comparison with (a) $\mathrm{S} / \mathrm{L}=0.2$ (b) $\mathrm{S} / \mathrm{L}=0.3$ (c) $\mathrm{S} / \mathrm{L}=0.4$

$C_{T}$ for $F_{r} 0.6589$ is lower than the $C_{T}$ for $F_{r}=0.66$ by $0.025 \%$. Referring to Fig. 10(a) for $F_{r}=0.6589$, there is weaker red colour happening in the middle of the two hull compared to $F_{r}=0.66$. Other than that, transversal pressure gradient (dark blue colour) is weaker at the stern for the optimized $F_{r}$ case.
$C_{T}$ for $F_{r}=0.6599$ is lower than the $C_{T}$ for $F_{r}=0.66$ by $0.0015 \%$. Referring to Fig. 10 (b) for $F_{r}=0.6599$, there is lower wave crest and the wave scatter more in the middle of two hull compared to $F_{r}=0.66$. Moreover, the wave generated by the stern of ship is lesser for the optimized $F_{r}=0.66$. 
$C_{T}$ for $F_{r} 0.6596$ is lower than the $C_{T}$ for $F_{r}=0.66$ by $0.086 \%$. This means that $F_{r}=0.6596$ had been optimized since its total resistance coefficient is lesser compared to existing $F_{r}=0.66$. Referring to Fig. 10 (c) for $F_{r}=0.6596$, the blue wave trough is more scatter compared to $F_{r}=$ 0.66 astern of the ship hull. Additionally, the wave generated in between the hull for $F_{r}=0.66$ and optimized $F_{r}$ was almost the same and not much difference.

Table 8. Total resistance coefficient for catamaran at $\mathrm{S} / \mathrm{L}=0.2$ to $0.4(\mathrm{Fr}=0.56)$

\begin{tabular}{cccc}
\hline $\mathrm{S} / \mathrm{L}$ & $F_{r}$ & Total Resistance Coefficient, $C_{T}$ & Discrepancy of $C_{T}(\%)$ \\
\hline 0.2000 & 0.009278935 & - \\
0.2125 & 0.009203327 & -0.81 \\
0.2250 & 0.009069646 & -1.45 \\
0.2375 & 0.008996420 & -0.81 \\
0.2500 & 0.009073417 & 0.86 \\
0.2625 & 0.008917622 & -1.72 \\
0.2750 & 0.008899929 & -0.20 \\
0.2875 & 0.008811081 & -1.00 \\
0.3000 & 0.56 & 0.008772445 & -0.44 \\
0.3125 & 0.008730137 & -0.48 \\
0.3250 & 0.008797172 & 0.77 \\
0.3375 & 0.008659397 & -1.57 \\
0.3500 & 0.008600827 & -0.68 \\
0.3625 & 0.008634891 & 0.40 \\
0.3750 & 0.008706303 & 0.83 \\
0.3875 & 0.008575417 & -1.50 \\
0.4000 & 0.008543530 & -0.37 \\
\hline
\end{tabular}

\subsection{Optimization of $S / L$ ratio in $F r=0.56$ and 0.66}

Based on Table 5, it is interesting to note that there is a great reduction of $C_{T}$ from Froude number 0.56 to 0.66 , which is $-13.16 \%$ for $\mathrm{S} / \mathrm{L}=0.2,-11.05 \%$ for $\mathrm{S} / \mathrm{L}=0.3$ and $-10.50 \%$ for $\mathrm{S} / \mathrm{L}=0.4$. The wave elevation decreases as shown in three of the cases. There is an interval of $\mathrm{S} / \mathrm{L}$ where at here resistance remains almost constant or even decreased particularly at $F_{r}=0.56$ and 0.66 . It is of great interest to find the optimum $\mathrm{S} / \mathrm{L}$ ratio happening between these two Froude numbers due to both the cases are of medium speed. The others Froude number are too rough. Design of Experiment (DOE) will be performed from $\mathrm{S} / \mathrm{L}$ $=0.2$ to $\mathrm{S} / \mathrm{L}=0.3$ and also $\mathrm{S} / \mathrm{L}=0.3$ to $\mathrm{S} / \mathrm{L}=0.4$ for 2 of the $F_{r} 0.56$ and 0.66 . There will be 4 results produced later. The existing $\mathrm{S} / \mathrm{L}$ will be $0.2,0.3$ and 0.4 .

\subsubsection{Case $\mathrm{Fr}=0.56$}

As viscous resistance interference was found to be relatively independent of speed and hull separation and rather is dependent on demi hull-length-to beam ratio. It is evident that a significant reduction in resistance could be achieved by finding the optimum position of stagger [12].

Table 9 below shows the comparison of total resistance coefficient for the optimized $\mathrm{S} / \mathrm{L}$ ratio with respect to $\mathrm{S} / \mathrm{L} 0.3$ and 0.4 . The computed wave patterns for the catamaran with optimized $\mathrm{S} / \mathrm{L}$ are presented in Fig. 11.

Table 9. Optimized S/L ratio in comparison with $\mathrm{S} / \mathrm{L} 0.3$ and 0.4 at $\mathrm{Fr}=0.56$

\begin{tabular}{ccccc}
\hline $\mathrm{S} / \mathrm{L}$ & $F_{r}$ & Total Resistance, $R_{T}$ & Total Resistance Coefficient, $C_{T}$ & Discrepancy of $C_{T}(\%)$ \\
\hline 0.29934 & \multirow{2}{*}{0.56} & 9.21970800 & 0.008718198 & - \\
0.30000 & & 9.27707560 & 0.008772445 & 0.62 \\
\hline 0.39885 & \multirow{2}{*}{0.56} & 9.00577420 & 0.008515901 & - \\
0.40000 & & 9.03499320 & 0.008543530 & 0.32 \\
\hline
\end{tabular}
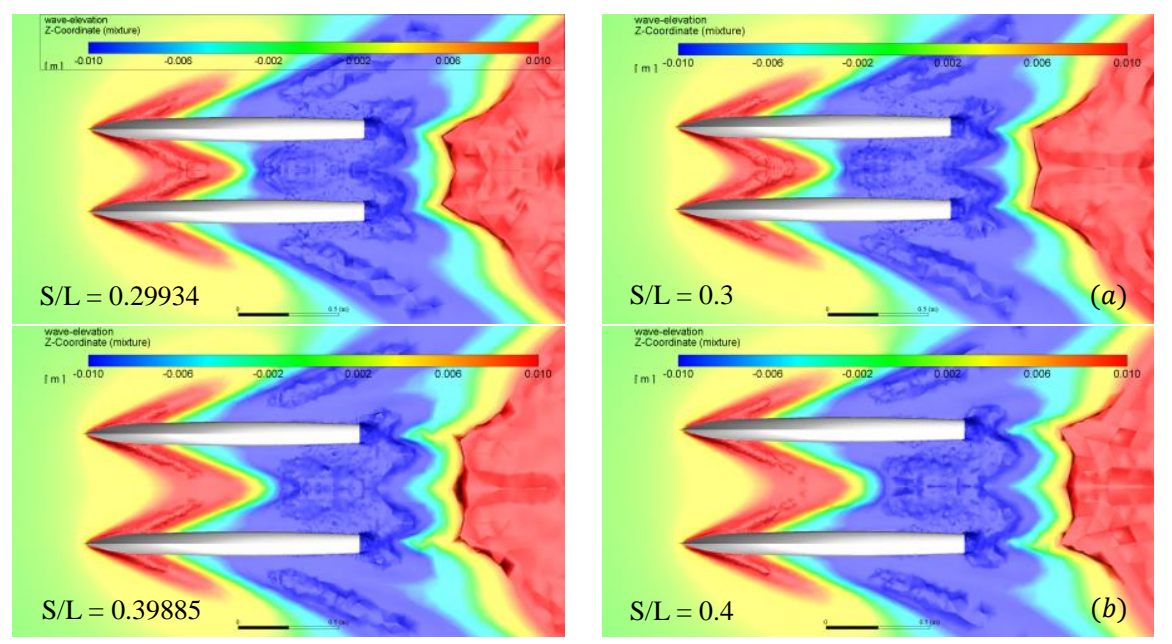

Figure 11. Wave patterns of optimized $\mathrm{S} / \mathrm{L}$ in comparison with (a) $\mathrm{S} / \mathrm{L}=0.3$ (b) $\mathrm{S} / \mathrm{L}=0.4$ 
Table 10. Total resistance coefficient for catamaran at $\mathrm{S} / \mathrm{L}=0.2$ to $0.4(\mathrm{Fr}=0.66)$

\begin{tabular}{cccc}
\hline S/L & $F_{r}$ & Total Resistance Coefficient, $C_{T}$ & Discrepancy of $C_{T}(\%)$ \\
\hline 0.2000 & 0.008057724 & - \\
0.2125 & 0.008091421 & 0.42 \\
0.2250 & 0.007973133 & -1.46 \\
0.2375 & 0.007948858 & -0.30 \\
0.2500 & 0.007867262 & -1.03 \\
0.2625 & 0.007998523 & 1.67 \\
0.2750 & 0.007791769 & -2.58 \\
0.2875 & 0.007806362 & 0.19 \\
0.3000 & 0.66 & 0.007803135 & -0.04 \\
0.3125 & 0.007695932 & -1.37 \\
0.3250 & 0.007699001 & 0.04 \\
0.3375 & 0.007719823 & 0.27 \\
0.3500 & 0.007649308 & -0.91 \\
0.3625 & 0.007745565 & 1.26 \\
0.3750 & 0.007620160 & -1.62 \\
0.3875 & 0.007763952 & 1.89 \\
0.4000 & 0.007646398 & -1.51 \\
\hline
\end{tabular}

Table 11. Optimized S/L ratio in comparison with $\mathrm{S} / \mathrm{L} 0.3$ and 0.4 at $\mathrm{Fr}=0.66$

\begin{tabular}{ccccc}
\hline $\mathrm{S} / \mathrm{L}$ & $F_{r}$ & Total Resistance, $R_{T}$ & Total Resistance Coefficient, $C_{T}$ & Discrepancy of $C_{T}(\%)$ \\
\hline 0.27500 & \multirow{2}{*}{0.66} & 11.4462310 & 0.007792202 & - \\
0.30000 & & 11.4622898 & 0.007803135 & 0.14 \\
\hline 0.37500 & \multirow{2}{*}{0.66} & 11.1810715 & 0.007611691 & - \\
0.40000 & & 11.2320536 & 0.007646398 & 0.46 \\
\hline
\end{tabular}
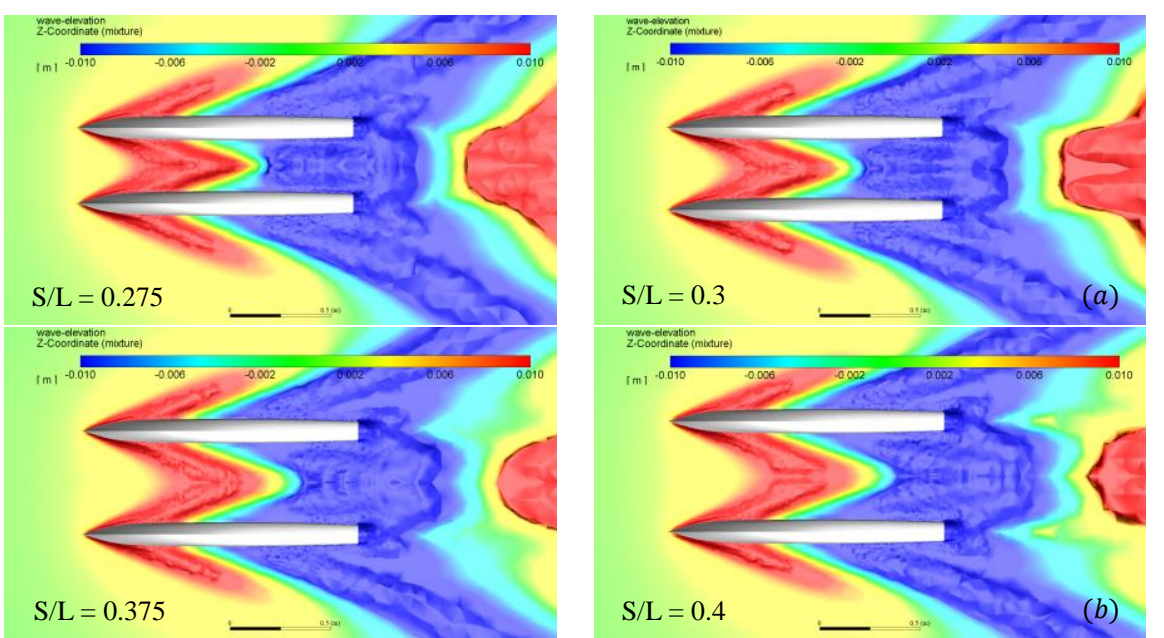

Figure 12. Wave patterns of optimized $\mathrm{S} / \mathrm{L}$ in comparison with (a) $\mathrm{S} / \mathrm{L}=0.3$ (b) $\mathrm{S} / \mathrm{L}=0.4$

From Table $9, C_{T}$ for $\mathrm{S} / \mathrm{L}=0.29934$ is lower than $C_{T}$ for $\mathrm{S} / \mathrm{L}=0.3$ by $0.62 \%$. Interference will cause wave superposition in the center wave profile of catamaran. But with the optimum distance of separation between the hull, there will be favourable resistance occurring. Figure 11(a) shows the lower wave elevation at ship stern for optimized $\mathrm{S} / \mathrm{L}=0.2993$ compared to $\mathrm{S} / \mathrm{L}=0.3$. Besides that, the blue colour wave trough is lower beside the two ship hull for the While $C_{T}$ for $\mathrm{S} / \mathrm{L}=0.3988$ is lower than the $C_{T}$ for $\mathrm{S} / \mathrm{L}=0.4$ by $0.32 \%$. Figure $11(\mathrm{~b})$ shows the lower wave elevation at ship stern for $\mathrm{S} / \mathrm{L}=0.3988$ compared to $\mathrm{S} / \mathrm{L}=0.4$. Higher and darker colour of wave trough beside the two ship hull for $\mathrm{S} / \mathrm{L}=0.3988$ proof that there is lower pressure exerted.

\subsubsection{Case Fr 0.66}

From Table 10, we can notice that the total resistance coefficient decreased from $\mathrm{S} / \mathrm{L}=0.2$ to 0.4 as general case. At a glance we can notice that $C_{T}$ for $\mathrm{S} / \mathrm{L}=0.275$ is lower than $C_{T}$ for $\mathrm{S} / \mathrm{L}=0.3 . C_{T}$ for $\mathrm{S} / \mathrm{L}=0.275$ will be
0.007791769 while $C_{T}$ for $\mathrm{S} / \mathrm{L}=0.3$ is 0.007803135 with a percentage difference of $0.14 \%$. On the other hand, S/L $=0.375$ has a lower total resistance coefficient compared to $\mathrm{S} / \mathrm{L}=0.4$. $C_{T}$ for $\mathrm{S} / \mathrm{L}=0.375$ will be 0.007620160 while $C_{T}$ for $\mathrm{S} / \mathrm{L}=0.4$ is 0.007646398 with a percentage difference of $0.34 \%$.

To verify it, manual running of ANSYS FLUENT is carried out. Table 11 below shows the comparison of total resistance coefficient for the optimized S/L ratio with respect to $\mathrm{S} / \mathrm{L} 0.3$ and 0.4 . The computed wave patterns for catamaran with optimized $\mathrm{S} / \mathrm{L}$ are presented in Fig. 12.

$C_{T}$ for $\mathrm{S} / \mathrm{L}=0.275$ is lower than the $C_{T}$ for $\mathrm{S} / \mathrm{L}=0.3$ by $0.14 \%$. Figure 12 (a) shows the darker blue colour wave generated in the middle of two ship hull, indicating lower pressure exerted. Also the pattern for red colour wave crest for optimized ratio 0.275 has smaller area.

As a result, the total resistance coefficient of optimized S/L ratio 0.375 is determined after verification. As we can see from Fig. 12(b), the lower wave elevation 
indicated by darker blue colour around ship stern for S/L $=0.375$ compared to $\mathrm{S} / \mathrm{L}=0.4$. Other than that, the yellow wave elevation for optimized $\mathrm{S} / \mathrm{L}$ ratio 0.375 is lower than that of $\mathrm{S} / \mathrm{L}=0.4$.

\section{Conclusion}

The Computational Fluid Dynamic investigation on the total resistance coefficients of the rounded catamaran was successfully performed ANSYS FLUENT software. The effects of lateral separation ratios were examined accordingly at a wide range of Froude numbers. Optimization of Froude number with respect to different $\mathrm{S} / \mathrm{L}$ ratio and optimization $\mathrm{S} / \mathrm{L}$ ratio is carried out at Froude number 0.56 and 0.66 . The computation results are drawn as follows:

- In general, the increase of lateral separation ratio from 0.2 to 0.3 dealt with less total resistance coefficient.

- $\mathrm{Fr}=0.65895$ is the optimized $\mathrm{Fr}$ for $\mathrm{S} / \mathrm{L}=0.2$.

- $\mathrm{Fr}=0.65995$ is the optimized $\mathrm{Fr}$ for $\mathrm{S} / \mathrm{L}=0.3$.

- $\mathrm{Fr}=0.6596$ is the optimized $\mathrm{Fr}$ for $\mathrm{S} / \mathrm{L}=0.4$.

- It is interesting to note that in $\mathrm{S} / \mathrm{L} \leq 0.3$, there is a tendency of optimized S/L ratio in Fr 0.56 and 0.66 .

- $\mathrm{S} / \mathrm{L}=0.29934$ is the optimized $\mathrm{S} / \mathrm{L}$ ratio between $0.2 \leq \mathrm{S} / \mathrm{L} \leq 0.3$ for case Fr 0.56 .

- $\mathrm{S} / \mathrm{L}=0.39885$ is the optimized $\mathrm{S} / \mathrm{L}$ ratio between $0.3 \leq \mathrm{S} / \mathrm{L} \leq 0.4$ for case $\mathrm{Fr} 0.56$.

- $\mathrm{S} / \mathrm{L}=0.275$ is the optimized $\mathrm{S} / \mathrm{L}$ ratio between 0.2 $\leq \mathrm{S} / \mathrm{L} \leq 0.3$ for case $\operatorname{Fr} 0.66$.

- $\mathrm{S} / \mathrm{L}=0.375$ is the optimized $\mathrm{S} / \mathrm{L}$ ratio between 0.3 $\leq \mathrm{S} / \mathrm{L} \leq 0.4$ for case Fr 0.66 .

\section{References}

[1] J. Van Hadler, C. Lee, J. Birmingham, and H. Jones, "Ocean Catamaran Seakeeping Design, based on the Experiments of USNS HAYES," 1974

[2] S. Asapana and N. Architecture, "Resistance Prediction for Asymmetrical Configurations of High-Speed Catamaran Hull Forms," 2015.

[3] K. Kenevissi, M. Atlar, and E. Mesbahi, "A New-generation Motion-control System for Twin-hull Vessels using a Neural Optimal Controller," Mar. Technol., vol. 40, pp. 168-180, 2003.

[4] S. E. Rollings, "Seakeeping Analysis of Small Displacement High-speed Vessels," Naval Postgraduate School Monterey Ca., 2003.
[5] A. Fitriadhy, S. A. Azmi, N. A. Mansor, and N. A. Aldin, "Computational Fluid Dynamics Investigation on Total Resistance Coefficient of A High-speed 'deep-V' Catamaran in Shallow Water," 2017.

[6] A. Fitriadhy, N. S. Razali, and N. A. Mansor, "Seakeeping Performance of a Rounded Hull Catamaran in Waves using CFD Approach," 2017.

[7] M. Insel and A. F. Molland, "An Investigation into the Resistance Components of High-Speed Displacement Catamarans," Trans. RINA, vol. 134, 1991.

[8] A. F. Molland, I. Utama, and D. Buckland, "Power Estimation for High-speed Displacement Catamarans," in International Conference on Marine Technology, 2000.

[9] P. K. Sahoo, L. J. Doctor, and L. Pretlove, "CFD Prediction of the Wave Resistance of a Catamaran with Staggered Demihulls," in Procs. of International Conference on Marine Hydrodynamics, 2006.

[10] A. Fitriadhy, S. P. Lim, and A. Jamaluddin, "CFD Investigation on Total Resistance Coefficient of Symmetrical and Staggered Catamaran Configurations through Quantifying Existence of an Interference Factor," 2016.

[11] Yanuar, Ibadurrahman, S. Karim, and M. Ichsan, "Experimental study of the interference resistance of pentamaran asymmetric side-hull configurations," 2017.

[12] S. I. Sohn, D. H. Park, Y. S. Lee, and L. K. Oh, "Hull Separation Optimization of Catamaran Unmanned Surface Vehicle Powered with Hydrogen Fuel Cell," Int. J. Phys. Math. Sci., vol. 6, no. 3, 2012.

[13] V. Anantha, "Choosing a Cat," pp. 69-82, 2006.

[14] ANSYS Release 18.1, Computing Forces, Moments, and the Center of Pressure. 2018.

[15] W. Froude, "On the Influence of Resistance upon the Rolling of Ship," Nav. Sci., p. 155, 1872.

[16] ITTC, "Report of the Performance Committee," 1957.

[17] ANSYS Release 18.1, Volume Fraction Equation. 2018.

[18] ANSYS Release 18.1, Transport Equations for the Standard $k-\varepsilon$ Model. 2018.

[19] K. Svanberg, "Method of Moving Asymptotes-A New Method for Structural Optimization," Int. J. Numer. Methods Eng., vol. 24, pp. 359-373, 1987.

[20] ANSYS Release 18.1, Central Composite Design (CCD). 2018.

[21] ANSYS Release 18.1, Genetic Aggregation. 2018.

[22] ANSYS, ANSYS Fluent Theory Guide.14.0. 2011.

[23] C. Janson and L. Larsson, "A Method for the Optimization of Ship Hulls from Resistance Point of View," in Proceedings Twenty-First Symposium on Naval Hydrodynamics, 1997.

[24] A. Papanikolaou and N. Dafnias, "Hydrodynamic Optimization and Design of a Fast Displacement Catamaran Ferry," in the 6th International on Marine Design Conference, 1997.

[25] A. F. Molland, J. F. Wellicome, and P. R. Couser, "Resistance Experiments on a Systematic Series of High Speed Displacement Catamaran Forms: Variation of Length-Displacement Ratio and Breadth-Draught Ratio,” 1994.

[26] V. A. Subramanian and P. Joy, "A Method for Rapid Hull Form Development and Resistance Estimation of Catamarans," Trans. Mar. Technol., vol. 38, no. 1, pp. 5-11, 2004.

[27] A. Molland, P. Wilson, D. Taunton, S. Chandraprabha, and P. Ghani, "Resistance and Wash Measurements on a Series of High Speed Displacement Monohull and Catamaran Forms in Shallow Water," Int. J. Marit. Eng., pp. 19-38, 2004. 